doi: $10.35366 / 97714$

\title{
Epigenética: la clave de la regulación genética
}

\author{
Epigenetics: the key to genetic regulation \\ Gabriela Rebeca Luna-Palencia,* Ismael Vásquez-Moctezuma ${ }^{\ddagger}$
}

\footnotetext{
* Departamento de Biotecnología y Bioingeniería del Centro de

Investigación y de Estudios Avanzados.

₹ Área de Morfología de la

Maestría en Ciencias de Salud de la Escuela Superior de Medicina.

Instituto Politécnico

Nacional, México, CDMX.
}

\begin{abstract}
RESUMEN
El estudio de la epigenética ha permitido explicar los procesos que conducen a diferentes enfermedades como el cáncer humano, la obesidad, la diabetes y otras más. Lo que ha entusiasmado a los investigadores de esta área es el hecho de que los cambios epigenéticos sobre el genoma son reversibles, lo que puede tener impacto positivo en la salud humana. Aquí se describen de manera muy general los diferentes procesos que logran la regulación genética como son la metilación y desmetilación del $\mathrm{ADN}$ en las islas $\mathrm{CpG}$, las modificaciones postraduccionales de las histonas, y los llamados micro ARN (miRNA) que cada día muestran su influencia en diferentes procesos normales y patológicos.
\end{abstract}

Palabras clave: Regulación epigenética, impronta genética, metilación, acetilación, miRNA.

\section{ABSTRACT}

The study of epigenetics has made it possible to explain the processes that lead to different diseases such as human cancer, obesity, diabetes and others. What has excited researchers in this area is the fact that epigenetic changes on the genome are reversible, which can have a positive impact on human health. Here the different processes that achieve genetic regulation are described in a very general way, such as, methylation and demethylation of DNA in the CpG islands, post-translational modifications of histones and the so-called micro RNA (miRNA) that each day shows their influence on different normal and pathological processes.

Keywords: Epigenetic regulation, genomic imprinting, methylation, acetylation, miRNA.
Correspondencia: Gabriela Rebeca LunaPalencia E-mail: galuna@cinvestav.mx

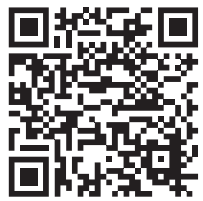

En abril de 2003, se concluyó la secuenciación del genoma humano mediante el Proyecto Genoma Humano, el cual dotó de la información básica para saber cómo los genes están posicionados en nuestros cromosomas. Sin embargo, aún era necesario saber cómo la información contenida en las secuencias de bases del ADN puede convertirse en proteínas y crear estructuras celulares y cómo se controla este proceso. Los mecanismos que controlan la expresión de unas proteínas y otras no, son tan importantes que básicamente, con la misma información en su genoma acerca de la síntesis de proteínas, se diferencian un tipo celular de otro y permiten la especialización. Estos mecanismos que mantienen la identidad de tejido y la función específica tienen que ver con la actividad del ADN sin alterar su secuencia de bases y no son explicados por la genética clásica. La actividad del ADN puede modificarse por el ambiente 
celular mediante procesos o reacciones químicas que se conocen como «mecanismos epigenéticos».

La palabra epigenética tiene el prefijo griego epi que significa en o sobre, dando a entender que estudia algo que está por fuera de lo que abarca la genética tradicional. En 1942, Conrad Waddington usó por primera vez el término «epigenética» y la definió como «una rama de la Biología que estudia las interacciones causales entre los genes y sus productos, los cuales dan el fenotipo a un organismo». En la actualidad, la definición más aceptada es que la epigenética «es el estudio de los cambios en la función genética que son mitóticamente y/o meióticamente heredables y que no implican un cambio en la secuencia del ADN». ${ }^{1} \mathrm{El}$ control genético se lleva a cabo por modificaciones covalentes reversibles entre las bases del ADN y las proteínas con las que se asocia en el núcleo, dando lugar a un nuevo código que es campo de estudio de la epigenética.

Es importante recalcar que los cambios genéticos son estructurales $y$, por tanto, irreversibles; mientras que los cambios epigenéticos en los que influye nuestro estilo de vida e impactan nuestra salud y la de generaciones futuras son funcionales $y$, por tanto, reversibles. Y existen grandes ejemplos de estos, quizás el más icónico fue conocido como la hambruna Holandesa referido como Dutch Hunger Winter en la Segunda Guerra Mundial, que fue consecuencia del bloqueo de alimentos y combustibles hacia Holanda occidental por parte de los alemanes, en el periodo de septiembre de 1944 hasta la liberación del país del dominio Nazi, en mayo de 1945. El bloqueo, aunado a un invierno crudo, originó muchas muertes; debido a que esta hambruna estuvo muy bien documentada, fue posible medir sus efectos en la salud humana, principalmente se pudo establecer una relación entre la falta de alimentación que sufrieron las mujeres embarazadas en esos momentos y la salud de su descendencia. Las investigaciones epidemiológicas encontraron que los niños nacidos de esas madres sometidas a dietas de inanición durante el embarazo dieron a luz a bebes que en su desarrollo mostraron ser más propensos a la diabetes, las enfermedades cardiacas y la obesidad, y mostraban ser más propensos a desarrollar enfermedades men- tales como esquizofrenia, respecto a los hijos de madres con buena alimentación durante el embarazo; ${ }^{2}$ además, la propensión a desarrollar estas enfermedades también se observaba en sus nietos. Estos hechos sugerían que la alimentación de la abuela podría afectar la salud de varias generaciones, implicando que una adaptación a su ambiente produjo un rasgo heredable, lo cual no era aceptable en ese momento, ya que sería un mecanismo de herencia que no se basaba en la modificación de la secuencia del ADN. ${ }^{1}$

Estudios demostraron que hay mecanismos de herencia que no implican cambios en la secuencia, sino que involucran modificaciones químicas del ADN y/o de la estructura de la cromatina, modulando la expresión de los genes, por lo que el fenotipo de cada individuo es resultado no sólo de su genoma sino también de su epigenoma. Ahora sabemos que lo que describió Waddington es, en gran parte, atribuible a mecanismos epigenéticos de regulación genética.

Algunos mecanismos epigenéticos que controlan la expresión genética incluyen la metilación del ADN, las modificaciones postransduccionales de las histonas y el silenciamiento por microRNA (miRNA), entre otros.

\section{METILACIÓN DEL ADN E IMPRONTA GENÓMICA}

La metilación del ADN ocurre cuando un grupo metilo $\left(-\mathrm{CH}_{3}\right)$ se une covalentemente al carbono 5 de la citosina en el ADN genómico por medio de una enzima conocida como DNMT (ADN metiltransferasa), que transfiere el grupo metilo de la S-adenosil metionina, para formar la 5-metil-citosina (Figura 1). En el humano se conocen tres metiltransferasas: Dnmt1, Dnmt3a y Dnmt3b. La enzima Dnmt1, tiene su actividad en los sitios de replicación y copia el patrón de metilación del ADN molde en la hebra hija recién sintetizada, por esta acción se le considera una metiltransferasa de mantenimiento de las metilaciones. La Dnmt3a y Dnmt3b son metiltransferasas de novo y tienen actividad de la metiltransferasa hacia el ADN no metilado. Normalmente estas enzimas DNMT se expresan en los tejidos de forma ubicua y en bajos niveles. ${ }^{3}$ Esta metilación se da más 
<smiles>Nc1cc[nH]c(=O)n1</smiles>

Citosina

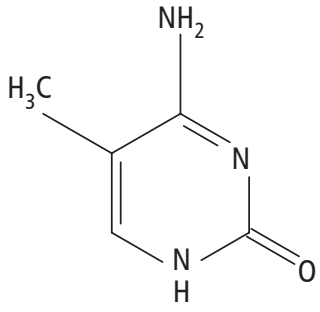

5-metil-citosina

Figura 1: Metilación de la citosina del ADN mediante la ADN metiltransferasa (DNMT).

en citosinas seguidas por guaninas (CG) en la secuencia nucleotídica. Cerca del 70-80\% de las CG del genoma humano están metiladas y se conocen como Islas CpG ( $p$ se refiere al fosfato entre las bases). Existen excepciones en las que las islas $\mathrm{CpG}$ están demetiladas como es el caso de la inactivación del cromosoma X en las mujeres y de los genes sujetos a impronta genómica. En estos casos, las islas CpG presentan metilación diferencial donde uno de los dos cromosomas está completamente metilado en las secuencias de las islas $\mathrm{CpG}$ mientras que la misma secuencia en el otro cromosoma está demetilado. $^{4}$

Las metilaciones del ADN constituyen marcas epigenéticas que lo modifican y pueden heredarse por la madre o el padre a la descendencia, esto se conoce como impronta genómica. En la reproducción sexual de los mamíferos, se heredan dos copias (alelos) de cada gen, uno de la madre y otro del padre, ambos son activos de manera transcripcional y funcional. Sin embargo, en la impronta genómica, sólo un alelo de cada gen es transcripcionalmente activo y el otro es silenciado, lo cual se establece en la línea germinal de cada progenitor durante la gametogénesis y se mantiene a través del desarrollo somático de la descendencia. Las marcas epigenéticas de cada línea germinal pueden controlar el silenciamiento o activación aleloespecífica de muchos genes vecinos, dando lugar a clusters en el genoma..$^{5}$ En 1991, se identificó el primer gen con impronta genómica en ratón, Igf2r (Insulin-like growth factor 2), expresado sólo del alelo materno. ${ }^{6}$ Todos los genes con impronta genómica muestran expresión monoalélica específica del padre o de la madre y su expresión correcta es esencial para que el desarrollo, el crecimiento fetal, el metabolismo y el comportamiento en la edad adulta sean normales. ${ }^{7}$

En humanos, el gen IGF2 (Insulin-like growth factor 2) también está sujeto a impronta genómica, por lo que sólo el alelo IGF2 paterno se transcribe en tejidos normales y la regulación de su expresión está dada por metilaciones en regiones conocidas como DMR (Differencially Methylated Regions), que son regiones ricas en CpG. La metilación solamente se presenta en el alelo heredado del padre a sus hijos y los cambios que ocurren en la metilación establecida en las DMR dan lugar a la pérdida de la impronta y a una transcripción alterada de IGF2. En 2013, se encontró que la obesidad del padre está asociada con una hipometilación de las DMR del IGF2; esta hipometilación también se encuentra en los hijos de padres obesos ${ }^{8} y$ en los hijos sexagenarios de las madres de la Hambruna Holandesa. ${ }^{1}$ Estos estudios sugirieron que factores como el estilo de vida de los padres se pueden transmitir a la siguiente generación por mecanismos epigenéticos.

Las regiones del genoma asociadas con metilación de las citosinas en las regiones promotoras junto con histonas marcadas con modificaciones represivas están reprimidas transcripcionalmente y se conocen como heterocromatina. En contraste, las regiones en las que las citosinas no están metiladas junto con modificaciones activadoras en las histonas se encuentran en un estado que permite la transcripción y se conoce como eucromatina. ${ }^{4}$

Generalmente, el nivel de metilación del ADN en la región promotora de un gen se correlaciona inversamente con la transcripción genética, ya que debido a la compactación de la cromatina no es posible el acceso de las proteínas de unión al ADN para el reco- 
nocimiento de la secuencia. En el caso de las células de cáncer, la metilación de las islas CpG en el promotor de los genes supresores de tumores no reprime la expresión, ya que ésta puede ser regulada por la unión de un factor de transcripción. ${ }^{9}$ Sin embargo, hay muchos datos que dan soporte a que la metilación en las islas CpG del promotor reprime la expresión genética, lo cual es reforzado por los hallazgos encontrados cuando las células con represión mediada por metilación son tratadas con inhibidores de las enzimas DNMT y muestran pérdida en la metilación en estas regiones $y$, en consecuencia, un incremento en la expresión genética. ${ }^{10-13}$

\section{MODIFICACIONES DE LAS HISTONAS}

En la mayoría de los núcleos de células eucariotas, el ADN tiene una longitud cercana a los dos metros, por lo que para poder mantenerse dentro del núcleo celular el ADN se compacta, formando la cromatina. La unidad fundamental de la cromatina es el nucleosoma, que consiste en un núcleo formado por un octámero de histonas, alrededor del cual se enrollan aproxi-<smiles>NC(CCCC[NH3+])C(=O)O</smiles>

Lisina
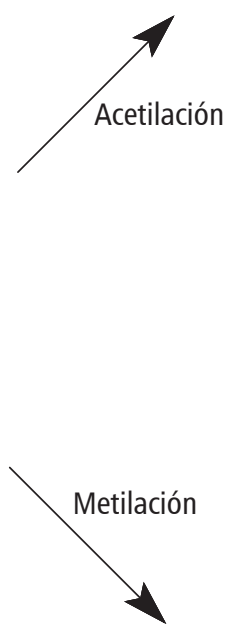

Figura 2:

Modificaciones epigenéticas de las histonas: acetilación y metilación de las lisinas presentes en los extremos N-terminal de las histonas.

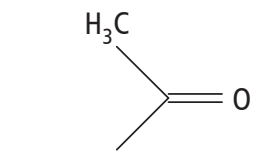<smiles>[R]OC(=O)C([NH])CCCCN</smiles>

Acetil-lisina<smiles>[R]OC(=O)C([NH])CCCC[NH+](C)C</smiles>

Trimetil-lisina 
madamente 147 pares de bases de ADN (ADN bicatenario), que corresponden a 1.7 vueltas. El octámero de histonas a su vez está constituido por un tetrámero central de proteínas $\mathrm{H} 3-\mathrm{H} 4$ asociados a dos dímeros proteicos $\mathrm{H} 2 \mathrm{~A}-\mathrm{H} 2 \mathrm{~B}$. Además, secciones pequeñas de ADN sirven para mantener a los nucleosomas unidos mediante una proteína de unión conocida como histona $\mathrm{H} 1$, dándole a la cromatina una apariencia de un collar de cuentas. El 75\% de la masa del octámero de histonas forma una estructura globular sobre la cual se envuelve el ADN, el 25\% restante consiste en las porciones $\mathrm{N}$-terminales de cada una de las ocho histonas, que se proyectan hacia afuera del nucleosoma y se conocen como «colas de histonas». Las colas de histonas, ricas en residuos de lisina y arginina, son susceptibles a modificaciones químicas que pueden regular la expresión de los genes, destacando por ser las más estudiadas hasta el momento, las acetilaciones y metilaciones de las lisinas (Figura 2); aunque también se cuentan las fosforilaciones, ubiquitinaciones, sumoilaciones y ADP-ribosilaciones. Estos procesos son mediados por enzimas que adicionan o remueven tales modificaciones, por ejemplo, las acetil transferasas de histonas (HAT) y las desacetilasas de histonas (HDAC) llevan a cabo el proceso de acetilación/desacetilación de histonas, modificando la estructura de la cromatina y en consecuencia, la expresión genética. Estas proteínas que adicionan o eliminan estas modificaciones postransduccionales se conocen como writters o erasers, respectivamente. Las HAT transfieren grupos acetilo que provienen de la acetil Co-A a los residuos de lisina de las colas de histonas (Figura 2); esta adición del grupo acetilo, neutraliza la carga positiva de los residuos de la lisina de las histonas, disminuyendo la atracción con el ADN (cargado negativamente), permitiendo el acceso a factores de transcripción y a la ARN polimerasa. Por otro lado, las HDAC remueven los grupos acetilo, disminuyendo la accesibilidad de factores de transcripción y de la ARN polimerasa. ${ }^{1,14,15}$ La mayoría de las HAT humanas funcionan como coactivadores de la transcripción. La función más estudiada de este grupo de proteínas es la acetilación de las colas de histonas, pero también se Conoce que poseen una función citoplásmica al acetilar varios factores de transcripción y otras proteínas. De la misma manera, las HDAC son conocidas fundamentalmente por desacetilar histonas, pero además tienen la capacidad de desacetilar otras proteínas, que se localizan de manera primordial en el citoplasma, como tubulina, p53, Hsp90, Bcl-2 y Ku70. ${ }^{16}$

Mientras que en la acetilación de histonas solamente se puede adicionar un grupo acetilo a una lisina $(K)$ en la cola $N$-terminal de la histona, en el proceso de metilación es posible mono-, di- o trimetilar una misma lisina (Figura 2). Por ejemplo, la histona $\mathrm{H} 3$ está trimetilada en la lisina 4 (H3K4me3) y es una marca de genes activos, en cambio, $\mathrm{H} 3 \mathrm{~K} 9 \mathrm{me} 3$ constituye una marca de heterocromatina ligada a genes inactivos; ${ }^{15}$ la lisina 9 de la histona 3 también puede acetilarse (H3K9ac) y es parte de una cromatina activa para la transcripción. ${ }^{1}$ Existe un sistema que refuerza la conformación de la cromatina acetilada y puede reducir la posibilidad de interacción de regiones adyacentes menos acetiladas y la llevan a cabo proteínas con bromodominios, que son módulos protéicos evolutivamente conservados que reconocen histonas acetiladas, se unen a ellas y reclutan a otras proteínas para mantener la conformación abierta de la cromatina para la transcripción. ${ }^{1}$

\section{MICRORNA}

Los microRNA (miRNA) son ARN pequeños de apenas 18 a 25 nucleótidos que no codifican y su función es reguladora, participan en procesos fundamentales del desarrollo, de diferenciación, de proliferación, de supervivencia y de muerte celular. ${ }^{17}$ Se ha visto que la expresión de éstos está desregulada en el cáncer y que son capaces de modificar el fenotipo de las células malignas. ${ }^{18}$

Las secuencias que codifican para esta gran familia de miRNA se localizan en las regiones intergénicas e intragénicas y son transcritos por la enzima ARN polimerasa II en cadenas sencillas de un tamaño que varía entre $1 \mathrm{a} 3 \mathrm{~kb}$; estos ARN largos se llaman pri-miRNA, éstos sufren un procesamiento adicional, a nivel del núcleo, por las ribonucleasas Drosha y la proteína Pasha que se une a este ARN de doble cadena. Esto genera un producto intermedio de entre 70 a 100 nucleótidos en forma de horquilla y plegado sobre sí mismo llamado pre-miRNA, el cual es conducido fuera del núcleo hacia el citoplas- 
ma por la proteína exportina 5 y Ran-GTPasa. En el citoplasma la enzima Dicer procesa el pre-miRNA generando fragmentos de ARN de 22 ribonucleótidos que se ensamblan en un complejo maduro llamado miRISC. La cadena guía de esta horquilla se forma por 21 a 22 nucleótidos de ARN, se asocian con las proteínas Argonauta y GW182 integrando el Ilamado complejo de silenciamiento inducido por ARN (RISC). Los miRNA hibridan complementado con sus secuencias blanco que se localizan en las regiones 3'no traducidas (3'UTR) de ARN mensajeros específicos. Posteriormente, ya con el complejo RISC asociado a su secuencia $3^{\prime}$-UTR, este ARN mensajero es degradado. ${ }^{19}$

\section{BIBLIOGRAFÍA}

1. Armstrong L. Post-translational modification of histones. In: Armstrong L ed. Epigenetics. New York; Garland Science. 2014. pp. 59-75.

2. Kyle UG, Pichard C. The Dutch Famine of 1944-1945: a pathophysiological model of long-term consequences of wasting disease. Curr Opin Clin Nutr Metab Care. 2006; 9 (4): 388-394.

3. Bogdanović O, Lister R. DNA methylation and the preservation of cell identity. Curr Opin Genet Dev. 2017; 46: 9-14.

4. Moylan CA, Murphy SK. DNA methylation basic principles. In: Tollefsbol T. eds. Medical Epigenetics. United Kingdom; Academic Press. 2016. pp. 11-29.

5. Wood AJ, Oakey RJ. Genomic imprinting in mammals: emerging themes and established theories. PLoS Gene. 2006; 2 (11): e147.

6. Barlow DP, Stöger R, Herrmann BG, Saito K, Scheweifer $\mathrm{N}$. The mouse insulin-like growth factor type-2 receptor is imprinted and closely linked to the Tme locus. Nature. 1991; 349 (6304): 84-87.

7. Li Y, Sasaki H. Genomic imprinting in mammals: its life cycle, molecular mechanisms and reprogramming. Cell Res. 2011; 21 (3): 466-473.
8. Soubry A, Schildkraut JM, Murtha A, Wang F, Huang Z, Bernal A et al Paternal obesity is associated with IGF2 hypomethylation in newborns: results from a Newborn Epigenetics Study (NEST) cohort. BMC Med. 2013; 11 (29): 1-10.

9. Moarii M, Boeva V, Vert JP, Reyal F. Changes in correlation between promoter methylation and gene expression in cancer. BMC genomics. 2015; 16 (1): 873.

10. Ferguson AT, Vertino PM, Spitzner JR, Baylin SB, Muller MT, Davidson NE. Role of estrogen receptor gene demethylation and DNA methyltransferase. DNA adduct formation in 5-aza-2'deoxycytidine-induced cytotoxicity in human breast cancer cells. J Biol Chem. 1997; 272 (51): 32260-32266.

11. Yamashita K, Upadhyay S, Osada M, Hoque MO, Xiao Y, Mori M et al. Pharmacologic unmasking of epigenetically silenced tumor suppressor genes in esophageal squamous cell carcinoma. Cancer Cell. 2002; 2 (6): 485-495.

12. Ibanez de Caceres I, Dulaimi E, Hoffman AM, AlSaleem T, Uzzo RG, Cairns P. Identification of novel target genes by an epigenetic reactivation screen of renal cancer. Cancer Res. 2006; 66 (10): 5021-5028.

13. Matsumura N, Huang Z, Mori S, Baba T, Fujii S, Konishi I et al. Epigenetic suppression of the TGF-beta pathway revealed by transcriptome profiling in ovarian cancer. Genome Res. 2011; 21 (1): 74-82.

14. Alberts B, Johnson A, Lewis J, Raff M, Roberts K, Walter P. Molecular biology of the cell. New York: Garland Science, 2008.

15. Sananbenesi F, Fischer A. Histone deacetylases as therapeutic targets in neurodegenerative diseases. In: Tollefsbol T. eds. Medical epigenetics. London, United Kingdom; Academic Press. 2016. pp. 33-45.

16. Robey RW, Chakraborty AR, Basseville A, Luchenko V, Bahr J, Zhan Zhirong et al. Histone deacetylase inhibitors: emerging mechanisms of resistance. Mol Pharmaceutics. 2011; 8 (6): 2021-2031.

17. Ambros $V$. The functions of animal microRNAs. Nature. 2004; 431 (7006): 350-355.

18. Garzon R, Marcucci G, Croce CM Targeting microRNAs in cancer: rationale, strategies and challenges. Nat Rev Drug Discov. 2010; 9 (10): 775-789.

19. Elliott D, Landomery M: Molecular Biology of RNA. Oxford University Press, 2016. 